\title{
Examining the Scientific Argumentation Implemented Through a Social Constructivism-Based Curriculum Designed for Primary Science Education in a Confucian Heritage Culture: A Case Study in Vietnam
}

\author{
Ngô Vũ Thu Hằng ${ }^{1}$, Astrid M.W. Bulte ${ }^{2}$, Albert Pilot ${ }^{2}$ \\ ${ }^{1}$ Hanoi National University of Education, Vietnam, 136 Xuan Thuy, Cau Giay, Ha Noi, Vietnam \\ ${ }^{2}$ Freudenthal Institute for Science and Mathemactics Education, The University of Utrecht, Princetonplein 5, 3584 CC \\ Utrecht, The Netherlands \\ Correspondence: Ngô Vũ Thu Hằng, Hanoi National University of Education, Vietnam, 136 Xuan Thuy, Cau Giay, Ha \\ Noi, Vietnam
}

Received: November 28, 2019 Accepted: April 21, 2020 Online Published: May 25, 2020

doi:10.5539/res.v12n2p64

URL: https://doi.org/10.5539/res.v12n2p64

\begin{abstract}
This study describes the improvement of a science curriculum based on a social constructivist approach in order to support primary students in a Confucian heritage culture in practicing scientific argumentation. The former design is adjusted by the application of an adapted model of the learning placemat for argumentation and by the formulation of concrete teaching-learning activities which are articulated with the application of the adapted learning placemat. The practice of a designed curriculum unit reveals that the designed curriculum can support the primary students in practicing scientific argumentation and in attaining consensually agreed knowledge. Nevertheless, the study also shows that primary teachers and students in a Confucian heritage culture do not pay much attention to the activities of qualifying and rebutting in scientific argumentation. The study recommends that further developmental research needs to deal with the refined problem of how to improve qualifying and rebutting in scientific argumentation in the practice of science lessons in a Confucian heritage culture.
\end{abstract}

Keywords: scientific argumentation, social constructivist approach, curriculum design, primary science education, confucian heritage culture

\section{Introduction}

The teaching and learning of science in a Confucian heritage $(\mathrm{CH})$ culture maintains a traditional approach which is teacher-centred, while students remain passive in constructing knowledge (Hằng, Meijer, Bulte, \& Pilot, 2015; Pham, 2019; Tao, Oliver, \& Venville, 2013). It is considered difficult to apply a social constructivist approach (SCA) to a community in which students have been passive in receiving data. $\mathrm{CH}$ is known to influence the teaching and learning with rote learning, the application of quotations and examples, and students' avoidance of confrontations and argumentation in discussion (Hằng et al., 2015). Yet there is a need for change and for policies to make advanced educational theories applicable in $\mathrm{CH}$ countries. The changes aim to help students be active and autonomous in constructing and grasping knowledge and skills; thereby, they can be well educated to be future labourers who can cope with the challenges of modern times and contribute to the development of $\mathrm{CH}$ countries. Coping with these issues, researchers call for curriculum development that takes cultural resources and local experiences into consideration (Coll \& Taylor, 2012) so that culturally appropriate pedagogies can be developed.

Derived from the above issues, a new curriculum for primary science education was designed, which was based on a SCA (Hằng, Meijer, Bulte, \& Pilot, 2017a). The curriculum design took the cultural divergences between a $\mathrm{CH}$ culture and Western educational philosophy into account (Hằng et al., 2015) and focussed on the "nature of science" with an emphasis on an inquiry-based approach (Abd-Al-Khalick \& Lederman, 2000). This is because what is called inquiry learning is very similar to what others call constructivist learning, and because the constructivist label can be applied to the nature of science learning and teaching (Anderson, 2007). The designed curriculum was put into practice through a programme of teacher professional development in Vietnam. The analysis of the first design cycle showed that the lessons could support $\mathrm{CH}$ students in becoming interested in science, curious about scientific subject matter, and both active and interactive in learning science (Hằng, Bulte, \& Pilot, 2019). However, despite considerable positive achievements, the first cycle curriculum design was not effective enough in supporting $\mathrm{CH}$ students in scientific 
argumentation (Hằng et al., 2019). Meanwhile, scientific argumentation is a core aspect of science education and stressed as necessary to students' learning of science (Driver, Asoko, Leach, Mortimer, \& Scott, 1994; Millar \& Osborn, 1998). However, there is a lack of studies on science curriculum innovations designed to support $\mathrm{CH}$ students in practicing scientific argumentation.

This study is the next step of a design-based research on designing a science curriculum based on a SCA for primary education in $\mathrm{CH}$ culture. It focuses on the issue of how to support $\mathrm{CH}$ students in practicing scientific argumentation through a social constructivism-based curriculum. This study aims to answer the main research question: To what extent does the adjusted design support $\mathrm{CH}$ students in practicing scientific argumentation in a science lesson and attaining consensually agreed knowledge? By giving answers for this questions, the study contributes to the development of a knowledge base for designing a social constructivism-based curriculum that supports scientific argumentation in primary science education in a $\mathrm{CH}$ culture.

\section{Understanding the Nature of Scientific Argumentation}

The use of scientific argumentation can support science teaching and learning that accomplishes much more than simply detailing what we know; it also teaches students how we know and why we believe (Driver et al., 1994; Millar \& Osborne, 1998; Osborne, Erduran \& Simon, 2004). This also aligns with the "nature of science" education, which emphasises the values of scepticism and open communication, as well as the interaction between personal beliefs in the generation of scientific knowledge.

Argumentation is understood as an interactional process of constructing an argument. Scientific argumentation can be perceived as a human practice that takes place as an individual activity through thinking and writing, and as a social activity within a group - a negotiated social act within a specific community (Driver, Newton, \& Osborne, 2000). Scientific argumentation involves the joining of two aspects - the personal and the social - and participants are required to construct and negotiate the meaning of the argument both privately and publicly (Hand, 2011), or personally and interpersonally. In this study, these two aspects are used to set up a framework that is utilised to analyse the practice of scientific argumentation among the students in a science lesson of the social constructivism-based curriculum designed for primary science education in a $\mathrm{CH}$ culture.

Regarding the personal aspect of scientific argumentation, the focus lies on arguments with the "solid" elements, such as data, evidence, causal structure, and causal coherence, which are used to formulate explanations and claims. These elements are synthesised from epistemic understandings of argumentation (Sandoval, 2005). According to Brian Hand (2011), data do not speak (p.46); data are facts that are involved in the argument to support the claim and to provide evidence used for reasoning. Both data and evidence cannot formulate explanations and arguments. To construct explanations in reasoning, causal structure and causal coherence are needed. Causal structure and causal coherence refer to the basic structure of an argument in sentences (Ryu \& Sandoval, 2012) and are represented by linking words such as because, since, on account of, and therefore (Toulmin, 1958). Causal coherence indicates the advancement of chains or networks of causal inferences in the scientific argument (Ryu \& Sandoval, 2012). It requires that the evidence and the epistemic claims in scientific arguments be connected coherently and consistently with each other.

Regarding the social aspect of scientific argumentation, the focus lies on the interpersonal activities that take place within a group of participants. In this sense, science is considered a process in which scientific knowledge is socially constructed, and in which discursive activity is central to the process of science (Driver et al., 2000). Therefore, an argument is perceived to be socially situated through argumentative activities such as evaluating, judging, qualifying, justifying, questioning, and rebutting. In this study, the definitions of these activities are as follows (Osborne, Erduran \& Simon, 2004; Toulmin, 1958):

- Evaluating: To ascertain or fix the value or worth of the claim or argument.

- Judging: To form an opinion or estimation of the claim or argument after careful consideration.

- Qualifying: To modify, limit, or restrict the claim or argument by giving exceptions or specifying the conditions under which the claim can be taken as true.

- Justifying: To demonstrate or prove the claim or argument to be right or valid.

- Questioning: To examine, analyse (a witness, for example), or interrogate the claim or argument; to express doubt about the claim or argument; to dispute the claim; or to show wonder or curiosity.

- Rebutting: To refute the claim by evidence or argument, or to oppose the claim by contrary proof or by specifying the conditions under which the claim will not be true.

It is difficult in practice to separate the activity of evaluating from the activity of judging and the activity of justifying from the activity of questioning. Therefore, in this study, to identify the students' practice of scientific argumentation, 
the activities of evaluating and judging are combined into one category called "evaluating and judging," and the activities of justifying and questioning are combined into another category called "justifying and questioning."

The personal and social aspects of scientific argumentation are considered two sides of a coin. Both of them need to be promoted in the practice of scientific argumentation (McComas, Almazroa, \& Clough, 1998). The practice of both the personal and social aspects of scientific argumentation in a science lesson can help students achieve consensually agreed knowledge more than can a traditional approach in which a body of factual knowledge is imposed on students. This is because through arguing with each other, students' scientific arguments and claims can be tested, justified, qualified, questioned, and rebutted. In this way, scientific knowledge is expected to find the best possible answers for students (Dekkers, 2006) rather than "correct" answers. Such learning of science is compatible with the "nature of science" education, which is defined as complex and subtle and contains no absolute truth (Abd-El-Khalick \& Lederman, 2000; Dekkers, 2006; Simon, Erduran \& Osborne, 2006). The expectation of achieving consensually agreed knowledge is considered to be suitable for a $\mathrm{CH}$ culture, because this culture values the collectivity, solidarity, and harmony that support consensus in communication (Hằng et al., 2015).

\section{Adjusting the Curriculum Design to Support Scientific Argumentation}

One of the learning aims of the designed curriculum is to help $\mathrm{CH}$ students acquire and develop argumentative skills. This is accomplished through the design of argumentative tasks as learning activities (Hằng, Bulte, \& Pilot, 2017b). Nevertheless, the implementation of the designed curriculum in practice revealed that this learning aim was not sufficiently achieved, since the students did not argue actively with each other although they were actively involved in the other learning activities (Hằng et al., 2019). The social activities of scientific argumentation such as evaluating, judging, qualifying, justifying, and rebutting were seldom carried out in the students' discussions. This low level of scientific argumentation in a social constructivist science lesson runs the risk of causing $\mathrm{CH}$ classrooms to return to the traditional approach in which the teacher transmits knowledge to students and students learn to reproduce "correct" answers.

The low level of scientific argumentation in the practice of the science lesson, especially with respect to its social aspect, was explained by two primary causes: a) the absence of a formulation of concrete teaching activities in the design that can serve as a specific guideline for teachers to implement teaching appropriately and support students in practicing scientific argumentation; and b) strong influences of a $\mathrm{CH}$ culture, which supports the harmony, stability, and hierarchy that cause students to avoid argumentation and conflicts in discussions (Hằng et al., 2017a).

\section{Adapting the Model of the Learning Placemat to the Design in order to Support Scientific Argumentation}

In thinking of adjusting the design, the designers searched for a pedagogical tool that could function as an intermediary between the designed formal curriculum and the teacher and students. Such a pedagogical tool should meet two primary criteria: i) supporting scientific argumentation in the practice of the science classroom, and ii) remaining appropriate within a $\mathrm{CH}$ culture, which values the stability and harmony that cause students to avoid arguing with each other. The pedagogical tool should effectively reconcile the divergences between the Western educational philosophy and a $\mathrm{CH}$ culture (Hằng et al., 2015; Mercier, Deguchi, Van der Henst \& Yama, 2016). Based on these criteria, the learning placemat (Bennett \& Rolheiser, 2001; Lissen, 2004) was selected and adapted to the design in a way that supports scientific argumentation in the practice of science lessons. The learning placemat is a sheet of paper with a space in the middle where students can write their common ideas. Around this middle space, the paper has empty areas in which students can first write their individual ideas. The learning placemat can involve groups of students working both alone and together to think about, record, and share their ideas, and to learn from each other in small group discussions. The adapted model of the learning placemat was used for argumentative activities in the cooperative hands-on task, as presented as in Figure 1. 


\begin{tabular}{|c|c|c|}
\hline $\begin{array}{l}\text { Individual ideas } \\
\qquad \text { Name: }\end{array}$ & $\begin{array}{c}\text { Individual ideas } \\
\text { Name: }\end{array}$ & $\begin{array}{l}\text { Individual ideas } \\
\qquad \text { Nam e: }\end{array}$ \\
\hline \multicolumn{3}{|l|}{ Hands-on } \\
\hline \multicolumn{3}{|l|}{$\begin{array}{l}\text { 1. What do you } \\
\text { observe? ......... }\end{array}$} \\
\hline \multicolumn{3}{|l|}{$\ldots .}$. \\
\hline \multicolumn{3}{|c|}{$\begin{array}{l}\text { 2. How can you explain your observation?/ Why is it like } \\
\text { that? }\end{array}$} \\
\hline \multicolumn{3}{|l|}{$\begin{array}{l}\text { 3. Do you have any } \\
\text { questions? ........... }\end{array}$} \\
\hline Name: & Nam e: & Name: \\
\hline Individual ideas & Individual ideas & Individual ideas \\
\hline
\end{tabular}

Figure 1. Adapted model of the learning placemat used in the design

The adapted model of the learning placemat is used in several steps, as presented below:

Step 1. Students in groups think independently and write down separate answers to the questions in the individual areas of the adapted learning placemat.

Step 2. Students share individual answers written on the adapted learning placemat with other members in the group as a whole.

Step 3. Students discuss individual answers in the group as a whole.

Step 4. Students select appropriate ideas from individual answers for the group's answers.

Step 5. Students write down the group's answers in the common area of the adapted learning placemat.

Step 1 can support and stimulate passive students to be more active and involved in learning. Step 2 can provide quiet and passive students with an easy way to share ideas, especially since their thoughts are visualised in written answers that these students can rely on to read and share with the group. In this way, the adapted model of the learning placemat can help reduce difficulties for students in expressing and arguing, and thus support them in becoming more confident in front of their peers and teacher. The last four steps of using the adjusted learning placemat can help students be more interactive and argumentative in the discussion, because they themselves have prepared their own answers.

With all of the steps of using the adapted learning placemat as described above, the adapted model of the learning placemat is considered to foster not only the personal aspect but also the social aspect of scientific argumentation. In addition, it can help teachers monitor the process of learning more smoothly and assess learning more conveniently. Through students' answers written on the adapted learning placemat, the teacher is provided with useful information to intervene appropriately when facilitating and assessing the learning individuals and groups.

\section{Formulation of Concrete Teaching-Learning Activities}

In adjusting the design, the teaching activities that $\mathrm{CH}$ teachers proposed (Hằng et al., 2017b) were used along with the students' learning activities. In addition, both the teaching and learning activities for the use of the adapted model of the learning placemat were articulated. In this way, the adjusted curriculum design provided a specific instructional framework (see Table 1) for primary science education in $\mathrm{CH}$ culture to support students in practicing scientific argumentation. Consequently, the adjusted design is considered a convenient teaching guideline for $\mathrm{CH}$ teachers to design and teach science lessons in accordance with a SCA and to foster students' scientific argumentation. The framework formed a basis on which to develop corresponding curriculum units and science lessons. 
Table 1 . The framework of a primary science curriculum based on a SCA for a $\mathrm{CH}$ culture

\begin{tabular}{|c|c|c|}
\hline Phase & Function & Teacher activity \\
\hline Engagement & $\begin{array}{lr}\text { A. To } & \text { provide } \\
\text { students } & \text { with } \\
\text { motivation } & \text { to }\end{array}$ & $\begin{array}{l}\text { i. Using a few key questions to reveal } \\
\text { students' prior knowledge and } \\
\text { curiosity related to the subject matter }\end{array}$ \\
\hline & $\begin{array}{l}\text { learn scientific } \\
\text { subject matter }\end{array}$ & ii. Staying open to students' responses \\
\hline
\end{tabular}
Student activity

1. Doing a small hands-on task with a relevant example related to scientific subject matter

2. Answering What, How, and Why questions about a relevant example related to scientific subject matter

iii. Delivering the task and being sure 3. PREDICTING and how to do the task iv. Establishing time for group discussion

v. Observing and supervising groups while they do their group tasks

vi. Encouraging students to present answers, and to compare and assess answers

B. To evoke attitudes toward science C. To acquire procedural

Experience D. To acquire conceptual knowledge E. To acquire argumentative skills vii. Staying open to students' responses

viii. Delivering the task and being sure that student groups know what to do and how to do the task

ix. Establishing time for group discussion

$\mathrm{x}$. Observing and supervising groups while they do their group tasks xi. Using open-ended elaborative questions to guide students xii. Staying open-minded and friendly to interact with students xiii. Encouraging students to present answers, and to compare and assess answers

F. To build on attitudes toward science

G. To build on procedural knowledge

Exchange

$\mathrm{H}$. To build on conceptual

knowledge I. To build on argumentative skills

xiv. Stimulating groups to interact and argue with each other

xv. Using open-ended elaborative questions to guide students to grasp deeper knowledge

xvi. Staying open-minded and friendly to interact with students xvii. Choosing representative questions formulated by students/groups for students to discuss and answer

J. To acquire cognitive

Follow-up flexibility K. To further learning motivation xviii. Providing open-ended sub-questions (if necessary) to guide students to answer/solve new questions/problems

xix. Giving compliments to individual students and groups who have achieved successful learning
3.1. Observing and discussing in order to answer questions: What do you observe? What will happen if...? Why do you think so?

3.2. Writing down answers (on the group small boards)

3.3. Presenting these answers $(3.1 \& 3.2$.) to other groups

3.4. Clarifying similarities and differences in answers for predicting questions among groups

3.5. Discussing the predicting answers with other groups

4. HANDS-ON

4.1. Doing the experiment and discussing the results in order to answer the questions: What did you observe? How can you explain your observations? Why do you think so?

4.2. Writing down answers in the individual ideas area of the adapted learning placemat

4.3. Sharing the written individual ideas in the group

4.4. Selecting ideas for the common answers and writing then down in the common ideas area of the adapted learning placemat

5. QUESTIONING: Formulating questions related to scientific subject matter

6. Presenting results of hands-on activities to other groups

7. Clarifying similarities and differences in answers (6)

8. Clarifying similarities and differences between predicting answers and hands-on answers within groups

9. Discussing results of the hands-on activities with other groups

10. Answering formulated questions related to scientific subject matter

11. Providing answers/solutions for questions/problems related to scientific subject matter 
The iterative teaching and learning activities presented in Table 1 show a spiral process of teaching and learning. In this way, the designed curriculum is considered to help $\mathrm{CH}$ students gradually acquire scientific knowledge, attitudes, and skills, especially argumentative skills.

\section{Research Questions}

This study was situated in Vietnam, a country deeply influenced by Confucianism that has recently implemented curriculum reform in primary education. Based on the arguments in the previous section, this study aims at answering the two interrelated research questions that appear below.

1. To what extent does the adjusted design of the social constructivism-based curriculum for primary science education in a CH culture support students in practicing scientific argumentation in a science lesson?

2. To what extent does the adjusted design support $\mathrm{CH}$ students in attaining consensually agreed knowledge on scientific subject matter?

\section{Research Strategy}

\subsection{Collaboration With CH Teachers}

This study is part of a research that applies a design-based approach (Bulte, Westbroek, De Jong, \& Pilot, 2006). It describes the second cycle of the design and research process. In this cycle, the preparation of the teachers was implemented collaboratively in a way rather similar to that used in the first cycle (Hằng et al., 2017b).

Three Vietnamese primary teachers who were involved in the first cycle of the design process continued to be involved in the second cycle one year later. The collaboration with the same teachers saved time and training because through the first cycle these teachers had already gained an understanding of ideas of the design and had adapted to some degree to social constructivist teaching after co-designing and teaching the experimental science lessons (Hằng et al., 2017b). With their existing knowledge and experiences, these teachers could more easily adapt to and accommodate the adjusted design. In this cycle, the teachers were informed about the adapted model of the learning placemat (Figure 1) and the concrete teaching-learning activities formulated in the design (Table 1).

The close collaboration between the researcher and the teachers took place in a work team in which the researcher acted as a leader. Much as they did with the original design in the first cycle, the teachers interacted with the adjusted design by co-designing and teaching science lessons based on curriculum units predesigned by the researcher. They were also involved in post-lesson discussions to reflect on the adjusted design and the experimental lessons.

\subsection{The Enactment of the Experimental Lessons}

Based on the curriculum framework (Table 1), three science curriculum units were designed for this cycle: Solutions, $\mathrm{CO}_{2}$ Reaction, and Plant Roots. The use of the units Solutions and $\mathrm{CO}_{2}$ Reaction aimed to provide the teachers with trial lessons. Although the teachers had already changed their approaches considerably toward a SCA (Hằng et al., 2017b), they needed time and experience to familiarise themselves with the changes to the adjusted design. In this way, they could teach the experimental lessons smoothly for the analysis of the adjusted design. In total, nine experimental science lessons were co-designed, taught and observed, and discussed in the collaborative team. Each of the experimental lessons was intensively discussed and evaluated by the team after being enacted in classroom practice. The main themes of the discussions were determined by the following questions:

1) What do you think about the lesson? Why do you think so?

2) What do you think about each of the phases in the lesson? Why do you think so?

3) What do you think about the teacher and students in this lesson? Why do you think so?

4) What should be done to improve the next lesson?

These questions were often elaborated in the discussions. By teaching and reflecting on the experimental lessons, each of the teachers could apply what was learned in the previous lesson to the next experimental lesson. Overall, the teachers made progress in the next lessons. On average, the enactment of the designed lessons was implemented in the span of a week.

\subsection{The Selection of the Best-Functioning Experimental Lesson for an In-Depth Analysis}

In order to find the best-functioning experimental lesson, key measuring criteria based on social constructivist features (Beck \& Kosnik, 2006) and used in the first cycle (Hằng et al., 2019) were used again in this cycle. In addition, one more criterion was established that focussed on scientific argumentation as the focal issue of the second cycle of the design process. These criteria were: 
i. The lesson is implemented in accordance with the designed lesson and consistent with the designed curriculum.

ii. The teacher implements attitudes and activities as a social constructivist teacher.

iii. Students are active and autonomous in learning.

iv. Social interactions are dominant in classroom practice and interactions among students are dominant for cooperative learning.

v. Knowledge is constructed by students through social negotiations.

vi. Students are argumentative in their interaction.

Based on these criteria, the team agreed that the ninth lesson of Plant Roots was the best-functioning of the experimental lessons. This lesson was therefore chosen for an in-depth analysis to answer the research questions.

The analysed Plant Roots lesson was taught by Vietnamese teacher T3, who was considered a competent teacher in a public primary school in Bacninh, a suburban area in Vietnam (Hằng et al., 2019). Teacher T3 was thirty years old and had eight years of experience teaching in primary school. The twenty-four Vietnamese students at the age of 10 were involved in this experimental lesson. The numbers of male and female students in this class were close to equal.

\subsection{Data Collection}

Data from two sources - classroom observations and learning materials - were collected. The details of data collection for this lesson are presented below.

A. Classroom observation. Classroom observation allowed the researcher to develop a holistic perspective on the implementation of the adjusted science curriculum based on a SCA. In this way, the researcher could see how scientific argumentation (for the first research question) was implemented by the students, and the extent to which the students attained consensually agreed knowledge in the lesson (for the second research question).

The researcher took photographs of the main activities taking place in the lesson for each of the phases of the adjusted design (see section Findings). One video camera was located at a convenient place in the classroom to have the best overview of how teaching and learning took place in the lesson. All of the students' group discussions in the lesson were recorded by audiotape to provide the researcher with data which were difficult to detect by observing the class from a distance. Voice recorders were put in the middle of the student tables to record discussions of the groups.

All of the videotapes and audiotapes were thereafter observed and listened to; subsequently, they were carefully transcribed verbatim if necessary and possible.

B. Learning materials. Learning materials were collected with the products completed by the students, including i) the groups' small boards (for the Engagement and Experience phases), ii) the learning placemats (for the Experience phase), and iii) the post-learning tests. In the post-learning tests, the students were asked to answer the following questions:

\section{1a. Can you provide some examples of taproot plants?}

1b. What is the taproot system? Make a drawing of the taproot system.

2a. Can you provide some examples of fibrous root plants?

$2 b$. What is the fibrous root system? Make a drawing of the fibrous root system.

The post-learning tests were delivered to the students and answered by them one month after the lesson.

\subsection{Data Analysis}

To answer the first research question - To what extent does the adjusted design support students in practicing scientific argumentation? - the defined activities of scientific argumentation were used as organising elements to cluster the students' utterances (Sources A \& B). The analysis mainly focussed on the Experience and Exchange phases, because scientific argumentation is the main expectation of these phases (Hằng et al., 2017a) that was not satisfied by the former design (Hằng et al., 2019). The students' practice of the personal aspect of scientific argumentation was analysed relied on the students' arguments written on the learning placemats (Source B). The students' practice of the social aspect of scientific argumentation was analysed relied on the data source of classroom observation (Source A), taken from either the video tape or the audio tapes. To analyse the way in which the students reasoned about root systems in their arguments, the designer's perspective of form and function in biology (Boerwinkel, Waarlo, \& Boersma, 2009) was used. Accordingly, the question of the form-function relation Why plant $X$ has root $Y$ and not $Y$ '? was a central focal point in analysing the reasoning in the students' arguments.

To answer the second research question - To what extent does the adjusted design support Confucian heritage students 
in attaining consensually agreed knowledge on scientific subject matter? - the answers and solutions provided by the students in the Exchange and Follow-up phases (Source A), as well as in the post-learning tests (Source B) were collected and assessed. To determine the students' consensually agreed knowledge on the plant roots, the assessment focussed on appropriate solutions and answers rather than "scientifically correct" answers.

The analysis of data sources was implemented in two cycles with many steps to validate the findings. The initial data analysis of the first cycle was accomplished by the first researcher. In this cycle, the first researcher provided the main findings of the lesson. Then the findings of the lesson were discussed with the teachers in the teachers-team. The discussion in the team provided a work-team consensus for the findings. After that, the second cycle of the analysis was carried out with the involvement of the research team.

In the second cycle, the data analysis was implemented in three main steps. Firstly, the first researcher discussed the first analysis and the findings which were agreed on by the teachers with the second researcher several times. After that, the researcher and the second researcher came to the first consensus on the analysis. Next, this analysis was discussed again between the first researcher and the third researcher. Their thorough discussions focussed on specific parts of the analysis and provided a deeper analysis of the lesson. The analysis was then carefully discussed in the entire research team to come to the final consensus. These discussions provided opportunities to cross-check and validate the findings thoroughly (Creswell, 2009). In this way, the thick description of the analysis of the lesson Plant Roots in practice was completed.

\section{Findings}

\subsection{Scientific Argumentation of the Students (Research Question 1)}

\section{Personal Aspects of Scientific Argumentation}

In total, 64 arguments were written by 24 students, individually or in groups. Specifically, for the prediction task, eight arguments were co-constructed by the four student groups; for the hands-on task, eight arguments were co-constructed by the four student groups and 48 arguments were constructed by individual students.

Data and evidence were provided in all of the students' arguments. They can be recognised in the students' arguments by the quantitative words, such as one and many, and the qualitative words, such as big, small, thin, and long, that the students used in their arguments related to the root systems of the mango and grass plants. Evidence is also recognised through the students' references to the shapes of the plant bodies or to the root functions to explain the forms of the root systems, as illustrated by the following examples:

- The mango has such a root system because it is suitable for the body of the mango which is straight, hard, and long. (Group 4)

- The mango has such a big root so that it can anchor the tree body stably on the ground. (Student Ha)

The body of the mango which is straight, hard, and long (in the argument of Group 4) and can anchor the tree body stably on the ground (in the argument of student $\mathrm{Ha}$ ) are considered evidence that the students used to provide explanations for their arguments.

Causal structure was found in 63 of the students' 64 arguments. This is presented by relationship-indicating causal words that the students used to construct their arguments. Specifically, the word because was used in 41 of the 64 arguments, the word therefore was used in 3 of the 64 arguments, and the words so that were used in 19 of the 64 arguments. For instance:

- The mango has such a root system [with the small roots attached to one long root] because it helps to convey nutrients for the tree. (Group 2)

- The grass has such a root system [many small and short roots] so that it can develop well. (Group 3)

Causal coherence was found in 47 of the students' 64 arguments. In these arguments, the students used relationship-indicating causal words plausibly. The students referred to the characteristics of the forms of the bodies of the mango and the grass in order to explain the forms of the root systems of these plants. For instance:

- $\quad$ The grass has a root system (many thin small roots) like that because it is suitable for its body which has many culms. (Student Hanh)

- The mango has a long and big root system because its body is big and tall. (Student Hanh)

- Also, the students referred to the functions of the root systems in order to explain the forms of the root systems of the mango and the grass. For instance:

- The grass's root system is many thin small roots so that it can help the plant reproduce well. (Student Lan) 
- The mango has a root system with one big long root and a few small roots around the big main root. This is because the big main root can help the mango not be blown down by a storm when it is growing. (Group 3 )

Both of the above arguments are considered as functional arguments in which the students referred to the functions of the root systems, such as the function of reproducing (in the argument of student Lan) or the function of anchoring (in the argument of Group 3), to explain the forms of the root systems.

In 17 of the 64 arguments presented by the students, the causal coherence was weak because of the use of inappropriate relationship-indicating words, the improper use of causal relationship-indicating words (i.e., the causal words were put in the wrong places), and mismatches between the subjects of inferences in the arguments. For instance:

- The root system of the mango has one big root and many small roots, long and sinuous, because the body of the mango is small so that the root system is also small. (Student Duy)

The above argument is not coherent in its content. It is not consistent with the form of the mango's root system described in the argument. In the first (pre-because) part of the sentence, the root system of the mango is described as having one big root and small roots but this does not claim that the mango has a small root system. However, in the second (post-because) part of the sentence (the body of the mango is small so that the root system is also small), which is used to explain the idea presented in the first part (the root system of the mango has one big root and many small roots, long and sinuous), the student claims that the root system of the mango is small. There is no logical relation between the ideas presented before because and those presented after it. The argument is therefore obscure.

Social Aspects of Scientific Argumentation

The students discussed and interacted with each other so enthusiastically and noisily in the group tasks that it was difficult to catch their ideas when listening to the voice recorders. Nevertheless, some of the audible conversations in the group discussions and classroom observations do reveal that the social aspect of scientific argumentation was implemented in this lesson.

Evaluating and judging were implemented by the students in all four of the groups in the Experience phase, especially when the students worked on the adapted learning placemats. It was observed that the common sequence of achieving group answers was generally implemented in a certain order. Firstly, each of the members in the group presented his/her personal answers (written in one of the individual areas on the learning placemat) to the questions. After that, ideas that differed from each other were evaluated and negotiated in the groups. Then the ideas the students agreed upon were written as the group's answers in the common area of the learning placemat. It was found that to formulate common answers to the questions, one group used nonverbal activities to indicate their agreement and disagreement with the personal ideas. This took place spontaneously when group members raised their hands if they agreed with an idea and did not raise their hands if they disagreed. This confirms the results of a study in Japanese CH schools by Merciet at al. (2016). The ideas consensually agreed upon were then written in the common area on the group's placemat. The nonverbal activity of raising hands is interpreted as the way in which the students evaluated the personal arguments to construct the argumentative answers of the group. Through this evaluation method, the students in the group achieved a consensus for the group's answers.

Words and phrases such as nice, right or not correct were heard on listening to conversations during the group discussions while students provided answers to the questions related to the hands-on activity. These words and phrases were interpreted as the activities of evaluating and judging when the students were arguing with each other. These activities are illustrated by the statements I think so too (Line 2), It's funny (Line 6), and Yes, I agree (Line 12) in Quotation 1 below.

In the overall class activity in the Exchange phase, the students demonstrated the activities of evaluating and judging. When asked to evaluate the answers of the groups, the students acknowledged that Group 4 formulated the best predictions: the outcomes of the hands-on activity were closest to their predictions.

Justifying and questioning were implemented by the students in all four of the groups. The activity of justifying was carried out when the students accomplished the hands-on task to justify their predictions about the root systems of the mango and the grass. This can be illustrated by an example from Group 2. The students in this group had two different kinds of ideas when they predicted the root system of the grass: one asserted that the grass has a big main root to help it adhere to the ground and the other asserted that the grass has many roots. After observing the root system of the grass, the student who held the idea that the grass has a big main root agreed that the grass has no big main root but many small thin roots.

In the discussion of Group 4, the students' activities of justifying and questioning were implemented in the expressions of student C (Line 4) and student A (Line 5) in Quotation 1 below. 
Quotation 1 A discursive dialogue (Group 4)

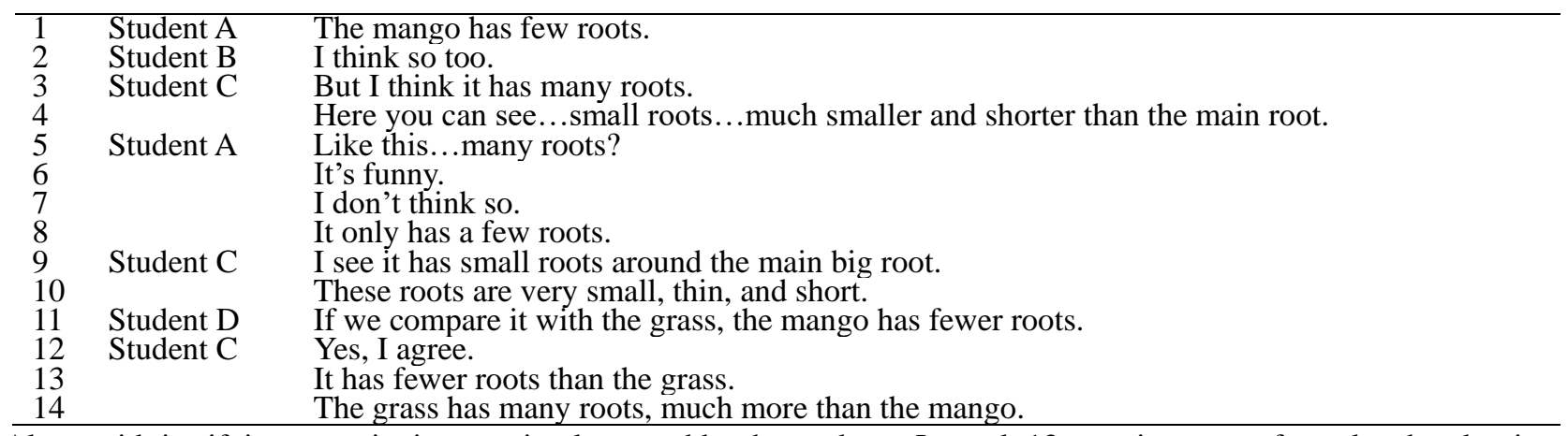

Along with justifying, questioning was implemented by the students. In total, 13 questions were formulated and written by the students on the learning placemats. Five questions were asked cooperatively and eight questions were asked individually, including: Could the mango live if it had the same root system as the grass? (Group 1); What would happen if the plant had no root system? (Group 2); Why does the mango have one root bigger than the root of the grass? (Group 3); and What do you think about the root system of an apple tree? (Group 4).

Rebutting was also implemented by the students when they argued with each other, as was recognised in the dialogue presented in Quotation 1. It was shown in the statement But I think it has many roots (Line 3) that student C offered to oppose the idea that the mango has few roots as asserted by students A and B (Lines $1 \& 2$ ), and again in the statement $I$ don't think so (Line 7) that student A offered to deny student C's idea that the mango has many roots.

Qualifying was implemented as well, and can be seen in the expression of student D (Line 11) and those of student C (Lines 13 \& 14) in Quotation 1.

Although Quotation 1 shows rebutting and qualifying, these activities could not be found in the conversations of the other groups in the Experience phase. In addition, in the whole class discussion in the Exchange phase, rebutting and qualifying could not be observed at all. Compared to the others activities of social argumentation, the students and teacher did not pay much attention to this. Although difficult to compare this seems to be in line with the observations at junior high schools in London (Osborne et al., 2004).

\subsection{Students'Attainment of Consensually Agreed Knowledge (Research Question 2)}

Through discussing, arguing with each other, and answering the elaborative questions asked by the teacher in the Exchange phase, which was organised in a spiral learning process with the other phases, the students could attain consensually agreed knowledge on plant roots. This can be recognised in Quotation 2 below.

Quotation 2 A teacher-student dialogue

\begin{tabular}{lll}
\hline Q1 & Teacher T3 & How many big roots does this mango have? \\
A1 & The class & One. \\
Q2 & Teacher T3 & What appears from this big root? (shows it by hand to the students) \\
A2 & The class & Small roots. \\
Q3 & Teacher T3 & What is this big root called? \\
A3 & The class & The main root. \\
Q4 & Teacher T3 & So...what is this type of root system called? ... Who knows? \\
A4 & Student E & Taproot. \\
Q5 & Teacher T3 & Why is it called taproot? \\
A5 & Student G & It is called the taproot system because its root system has few roots and is not exuberant. \\
Q6 & Teacher T3 & Can you describe it more clearly? \\
A6 & Student E & It has one long and big root with small roots surrounding it. \\
Q7 & Teacher T3 & Do you agree with her? \\
A7 & The class & Yes. \\
Q8 & Teacher T3 & So...what is the taproot system? \\
A8 & Student H & The taproot system is the one having a main root, hard, long, and sticking deeply into the \\
& & ground. \\
Q9 & Teacher T3 & Anything else? \\
A9 & Student I & And having many small roots surrounding it. \\
\hline
\end{tabular}

As in the conversation quoted above, the teachers asked many questions for the students to answer. The questions could be 
developed and elaborated from students' initial answers (as, for instance, in Q5, Q6, Q7, Q8, \& Q9). This enabled students' answers to be interconnected with each other (in, for instance, A4, A5, A6, A7, \& A8). In this way, the students gradually came to a conceptualisation of the taproot and fibrous root systems.

The findings in the Exchange phase are consistent with the findings in the Follow-up phase, in which the students were asked by the teacher to assess the drawings made in the Engagement phase. The students recognised the inappropriateness of the root systems in the drawings of the plants they had made before being involved in the inquiry activities of the Experience phase and the discussions of the Exchange phase. In the Follow-up phase, they proposed solutions to adjust the drawings, as shown by the example drawings presented in Figure 2.

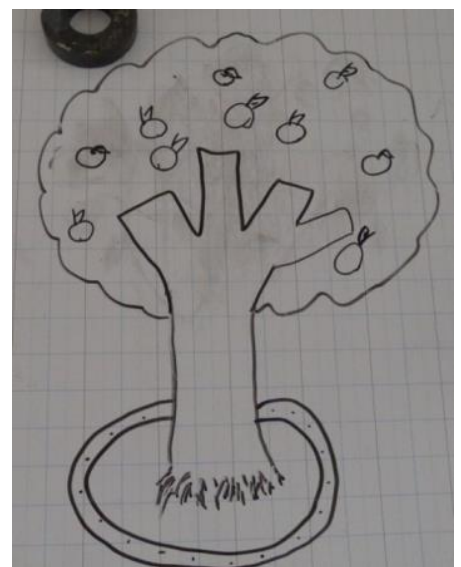

1. Before - in the Engagement phase

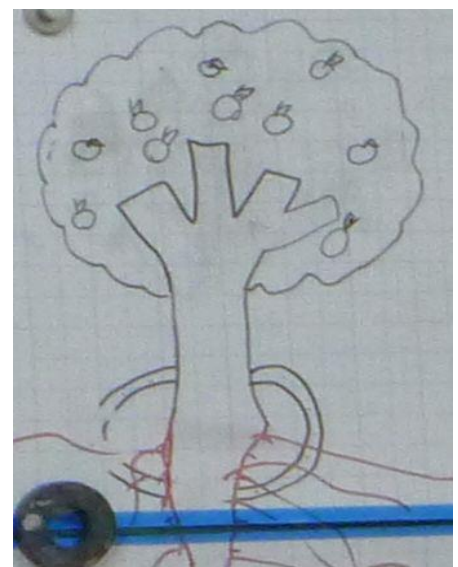

2. After - in the Follow-up phase

Figure 2. The drawings of a complete plant made by the students

As seen in Figure 2, the root system of the apple tree that the students drew at the beginning of the lesson in the Engagement phase was very short and thin (Figure 2.1). However, at the end of the lesson, in the Follow-up phase, the drawing of the root system of the apple tree was adjusted by the students: the root system was drawn with a bigger and longer root and many small and thin sub-roots (Figure 2.2).

Moreover, when asked to determine the root type of the real radish provided by the teacher, the students were enthusiastic in providing answers and all of the answerers acknowledged that the radish had a taproot system because they saw that the radish had one big root at the foot of the plant with a few small roots sprouting from the main root. The appropriate answers of the students in the Follow-up phase showed that they had attained consensually agreed knowledge on the types of plant roots.

The findings from class observation were consistent with the students' answer sheets in the post-learning test. On the day of doing the post-learning test, twenty-two of the 24 students were available in the classroom and took the post-learning test.

Twenty-two of the 22 students who completed the test provided 79 examples of the taproot system using 17 different plants. Seventy-seven of the 79 examples are the kind of trees that have large, tall straight bodies, including apple (18 times in the examples), mango (16 times), orange (16), flamboyant (6), jackfruit (3), Malabar almond (3), guava (3), mandarin (3), khaya senegalensis (African mahogany, 2), star apple (2), grapefruit, mandarin orange tree, pear, mangosteen, and durian (once each). The two other examples provided for the taproot system were grape and kohlrabi. This is consistent with 17 of the 22 answers provided by students for the test question What is the taproot system? These answers were simple conceptualisations of the taproot system but nonetheless reflected the main characteristics of the taproot system, as in the following quotation:

- The taproot system consists of one main root and many lateral roots. The main root is bigger and longer than the lateral roots. It helps to anchor the plant to the ground. (Student Hoang)

Such a conceptualisation of the taproot system aligns with all of the drawings of the taproot system made by the 22 students, as represented by the drawing in Figure $3 \mathrm{a}$.

The 22 students also provided 58 examples of the fibrous root system using 16 different plants. Twenty-six of these 58 examples are the kind of plants that have small short bodies, including grass (14 times in the examples), rice (5 times), water spinach (3), salad greens (3), and onion (once). Thirty of the 58 examples provided for the fibrous root system are large, tall trees, including the banian tree (18 times), Benjamin fig (4), khaya senegalensis (African mahogany, (2), 
flamboyant, papaya, Malabar almond, rubber tree, cardamom, and grapefruit (once each). The two remaining examples indicated "luffa" and "flower." Although the students provided examples of the fibrous root system using plants with large, tall bodies that were also considered by them to belong to the taproot system - namely, khaya senegalensis (African mahogany), flamboyant, Malabar almond, and grapefruit - 18 of the 22 answers for the test question What is the fibrous root system? provided by the students can reflect the main characteristics of the fibrous root system, despite simple conceptualisations, as illustrated in the following quotation:

- The fibrous root system consists of many roots sprouting from the foot of the plant; the majority of them are similar to one another. (Student An)

Such a conceptualisation of the fibrous root system aligns with all of the drawings of the fibrous root system made by the 22 students, as represented by the drawing in Figure 6 b.

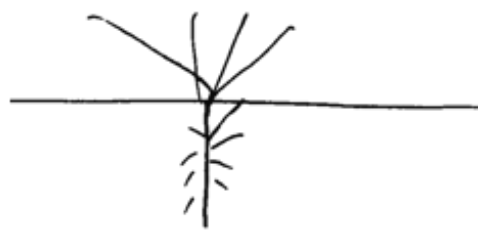

a. Taproot system

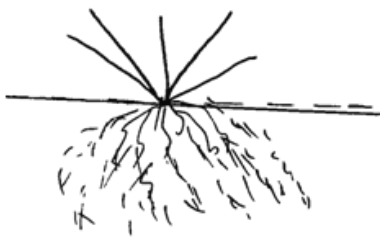

b. Fibrous root system

Figure 3. Students' drawings of root systems

Based on the way in which the students conceptualised the taproot and fibrous root systems and on their illustrative drawings, considered as the appropriate answers on applying knowledge of the students, the researcher considered that the students attained consensually agreed knowledge of the taproot and fibrous root systems.

\section{Conclusions and Discussion}

This study shows that the adjusted design can substantially support $\mathrm{CH}$ students in practicing scientific argumentation (research question 1) and attaining consensually agreed knowledge (research question 2). Thereby, this study delivered a proof of principle (Westbroek, Klaassen, Bulte, \& Pilot, 2010) for the adjusted curriculum. In this way, the study shows that the design with its concrete teaching-learning activities can indeed be a possibility for application to primary science education in a $\mathrm{CH}$ culture. It can be used to activate student learning and support students in practicing scientific argumentation, and seems a promising contribution to the improvement of primary science education that addresses the analysed problems (Hằng et al., 2015) and the refined problem (Hằng et al., 2019). Moreover, this study shows that the adapted model of the learning placemat is a culturally appropriate teaching-learning tool that is useful in facilitating $\mathrm{CH}$ students to interact with each other and practice scientific argumentation. Although specifically designed for a $\mathrm{CH}$ culture, the adapted model of the learning placemat could be useful for learning scientific argumentation in other cultures as well because it is so easy to use. Therefore, the adapted model of the learning placemat is recommended for use in facilitating students to practice scientific argumentation.

Although the adjusted curriculum substantially supported $\mathrm{CH}$ students in practicing scientific argumentation, this study revealed that regarding the personal aspect of scientific argumentation, the causal coherence of an argument needs attention in instruction, because causal coherence was less effectively implemented by the students compared to the other indicators of the personal aspect. Regarding the social aspect of scientific argumentation, this study showed that $\mathrm{CH}$ students seldom practiced the argumentative activities of qualifying and rebutting. The low level of implementation with respect to qualifying and rebutting emerged as the refined problem in the second cycle design. It can be considered as the core problem of applying a SCA in primary science education in a $\mathrm{CH}$ culture, and needs further research, because qualifying and rebutting are essential activities of scientific argumentation (Hand, 2011; Toulmin, 1958). The findings of this study reinforce the proposition that scientific argumentation is difficult in science education (Driver et al., 2000; Osborne et al., 2004). Further research is recommended to deal with the problem of how to embed the activities of qualifying and rebutting in scientific argumentation in a science lesson based on a SCA.

In thinking of supporting the activities of qualifying and rebutting in science lessons, it is possible to use the learning placemat as a pedagogical tool. The recommendation is to extend the learning placemat with scaffolding questions that specifically focus on qualifying and rebutting, as shown in Figure 4. 


\begin{tabular}{|c|c|c|}
\hline $\begin{array}{l}\text { Individual ideas } \\
\text { Name: }\end{array}$ & $\begin{array}{c}\text { Individual ideas } \\
\text { Name: }\end{array}$ & $\begin{array}{r}\text { Individual ideas } \\
\text { Name: }\end{array}$ \\
\hline \multicolumn{3}{|c|}{ What are your group's arguments to qualify and/or rebut the given argument? } \\
\hline Name: & Name: & Name: \\
\hline Individual ideas & Individual ideas & Individual ideas \\
\hline
\end{tabular}

Figure 4. The adapted model of the learning placemat for supporting qualifying and rebutting

Along with the use of learning placemat, to support students in practicing the activities of qualifying and rebutting, teachers are recommended to pose the following reassuring and challenging questions:

- You are intelligent/smart/bright if you can rebut/show the limitations of this argument. Who can do it?

- Who can add to the incomplete argument/statement?

- Can you show an example of why this claim is not completely correct?

- I expect that one of you can provide an argument which is more coherent/persuasive.

- You are welcome to provide rebuttals to arguments.

- It is a difficult job, but who can rebut this argument convincingly?

- Rebutting and showing limitations of an argument are difficult jobs and you are a good scientist if you can do such difficult jobs. Can you do this with the last argument?

The above questions and statements can be considered to encourage and motivate students to provide more coherent arguments and practice qualifying and rebutting in their argumentation in science classes. If these questions and statements are emphasised and regularly expressed by the teacher in a social constructivist science class, students can gradually become more familiar with the activities of qualifying and rebutting; hence, their argumentative skills can be enhanced. In addition, the analysis of the quality of arguments plays an essential role and needs to have appropriate frameworks for analysis. Lakatos' scientific research programmes (Chang \& Chiu, 2008), may add to the theoretical framework for representing and evaluating informal argumentation, and could offer an alternative in supporting the improvement of quality of scientific arguments.

With its adjusted design of a social constructivism-based curriculum incorporating concrete teaching-learning activities, this study is a response to the call for tighter structuring and scaffolding of students' activities than most social constructivists envision (Brophy, 2006). Concrete teaching-learning activities can meaningfully clarify theoretical frameworks, which can then be discussed and compared (Klaassen \& Kortland, 2013), who argue that the nature of theory in connection with curriculum design is often unclear. With the concrete teaching-learning activities as an application of a social constructivist perspective, this study aligns with the implications many researchers have formulated for a design-based research approach (Kortland \& Klaassen, 2010; Méheut \& Psillos, 2004; Osborne et al., 2004). Moreover, the design with its concrete teaching-learning activities makes a social constructivism-based curriculum easier to use in the practice of primary science education in a $\mathrm{CH}$ culture. It bridges a gap between the ideal and formal curriculum and the experiential and attained curriculum (Van den Akker, 2003). By providing the specific design with concrete teaching-learning activities and identifying which elements of scientific argumentation are key issues, the study provides a first and essential step to a knowledge base about designing and implementing a science curriculum based on a SCA that supports scientific argumentation in primary science education in $\mathrm{CH}$ cultures.

\section{Acknowledgements}

The researchers would like to thank Dirk-Jan Boerwinkel for his discussion on the perspective of form and function and functional arguments that has been extremely useful for this study.

Endnotes

All names of the teachers and the students used in this study are pseudonyms. 


\section{Compliance with Ethical Standards:}

The authors assure that this research paper was done in compliance with Ethical Standards.

\section{Conflict of Interest:}

The authors declare that they have no conflict of interest in this research.

\section{References}

Abd-El-Khalick, F., \& Lederman, N. G. (2000). Improving science teachers' conceptions of nature of science: A critical review of the literature. International Journal of Science Education, 22(7), 665-701. https://doi.org/10.1080/09500690050044044

Anderson, R. D. (2007). Inquiry as an organizing theme for science curricula. In S. K. Abell \& N. G. Lederman (Eds.), Handbook of research on science education (pp. 807-830). Oxford, UK: Taylor \& Francis.

Beck, C., \& Kosnik, C. (2006). Innovations in teacher education - A social constructivist approach. Albany, NY: State University of New York Press.

Bennett, B., \& Rolheiser, C. (2001). Beyond Monet: The artful science of instructional integration. Toronto, ON: Bookation.

Boerwinkel, D. J., Waarlo, A. J., \& Boersma, K. (2009). A designer's view: The perspective of form and function. Journal of Biological Education, 44(1), 12-18. https://doi.org/10.1080/00219266.2009.9656186

Brophy, J. (2006). Graham Nuthall and social constructivist teaching: Research-based cautions and qualifications. Teaching and Teacher Education, 22, 529-537. https://doi.org/10.1016/j.tate.2006.01.008

Bulte, A. M. W., Westbroek, H. B., De Jong, O., \& Pilot, A. (2006). A research approach to designing chemistry education using authentic practices as contexts. International Journal of Science Education, 28(9), 1063-1086. https://doi.org/10.1080/09500690600702520

Chang, S., \& Chiu, M. (2008). Lakatos' scientific research programmes as a framework for analyzing informal argumentation about socio-scientific issues. International Journal of Science Education, 30(13), 1753-1773. https://doi.org/10.1080/09500690701534582

Coll, R. K., \& Taylor, N. (2012). An international perspective on science curriculum development and implementation. In B. J. Fraser, K. G. Tobin, \& C. J. McRobbie (Eds.), Second international handbook of science education (Vol. II, pp. 771-782). Dordrecht, Netherlands: Springer. https://doi.org/10.1007/978-1-4020-9041-7_51

Creswell, J. W. (2009). Research design: Qualitative, quantitative, and mixed methods approaches (3rd ed.). Thousand Oaks, CA: Sage Publications.

Dekkers, P. (2006). Reconstructing the creature - Exploring design criteria for teaching NOS. In E. V. Den Berg, T. Ellermeijer, \& O. Stooten (Eds.), Proceedings of the GIREP Conference Modelling in Physics and Physics Education (pp. 459-464). Amsterdam, Netherlands: University of Amsterdam.

Driver, R., Asoko, H., Leach, J., Mortimer, E., \& Scott, P. (1994). Constructing scientific knowledge in the classroom. Educational Researcher, 23(7), 5-12. https://doi.org/10.3102/0013189X023007005

Driver, R., Newton, P., \& Osborne, J. (2000). Establishing the norms of scientific argumentation in classrooms. Science Education, 84, 287-312. https://doi.org/10.1002/(SICI)1098-237X(200005)84:3<287::AID-SCE1>3.0.CO;2-A

Hand, B. (2011). An immersion approach to argument-based inquiry - Does it look the same in different countries? In Y. Kim, J. Park, H. E. Seo, J. A. Lee, \& J. Kim (Eds.), Proceedings of the 2011 EASE International Conference Lighting the world with science (pp.45-54). Chosun University, Gwangju, Korea.

Hằng, N. V. T., Bulte, A., \& Pilot, A. (2017b). Interaction of Vietnamese teachers with a social constructivism-based primary science curriculum in a framework appropriate for a Confucian heritage culture. Asia-Pacific Science Education, 3(2), DOI 10.1186/s41029-017-0013-0. DOI 10.1186/s41029-017-0013-0.

Hằng, N. V. T., Bulte, A., \& Pilot, A. (2019). Implementation of a primary science curriculum designed in accordance with a social constructivist approach for Vietnamese Confucian heritage culture. Journal of Physics: Conference series, 1340(1). https://doi.org/10.1088/1742-6596/1340/1/012028

Hằng, N. V. T., Meijer, M. R., Bulte, A., \& Pilot, A. (2015). The implementation of a social constructivist approach in primary science education in Confucian heritage culture: the case of Vietnam. Cultural Studies of Science Education, 10(3), 665-693. https://doi.org/10.1007/s11422-014-9634-8

Hằng, N. V. T., Meijer, M. R., Bulte, A., \& Pilot, A. (2017a). Designing a primary science curriculum in a globalising 
world: how do social constructivism and Confucian heritage culture meet? Cultural Studies of Science Education, 12(3), 739-760. https://doi.org/10.1007/s11422-015-9696-2

Klaassen, K., \& Kortland, K. (2013). The role and nature of theory in design research. Paper presented at the $13^{\text {th }}$ ESERA Conference: Science education research for evidence-based teaching and coherence in learning. Cyprus University, Cyprus.

Kortland, J., \& Klaassen, K. (Eds.). (2010). Designing theory-based teaching-learning sequences for science education. Utrecht, Netherlands: CD $\beta$ Press. Retrieved from http://www.staff.science.uu.nl/ kortl101/book_sympPL.pdf

Lissen, L. (2004). Co-operative learning, a 'tool' for both students and teachers. In R. Schollaert (Ed.), The keys to the treasure within: Learning and leadership in schools (pp.101-110). Antwerp, Belgium: Garant-Uitgevers.

McComas, W. F., Almazroa, H., \& Clough, M. (1998). The nature of science in science education: An introduction. Science and Education, 7, 511-532. https://doi.org/10.1023/A:1008642510402

Meheut, M. \& Psillos, D. (2004). Teaching - learning sequences: aims and tools for science education research. International Journal of Science Education, 26(5), 515-535. https://doi.org/10.1080/09500690310001614762

Mercier, H., Deguchi, M., Van der Henst, J. B., \& Yama, H. (2016). The benefits of argumentation are cross-culturally robust: The case of Japan. Thinking and Reasoning, 22(1), 1-15. https://doi.org/10.1080/13546783.2014.1002534

Millar, R., \& Osborne, J. F. (Eds.). (1998). Beyond 2000: Science education for the future. London, UK: King's College.

Osborne, J., Erduran, S., \& Simon, S. (2004). Enhancing the Quality of Argumentation in School Science. Journal of Research in Science Teaching, 41(10), 994-1020. https://doi.org/10.1002/tea.20035

Pham, T. N. (2020). Electronic Peer Feedback, EFL Academic Writing and Reflective Thinking: Evidence From a Confucian Context. SAGE Open 2020, 1-20. https://doi.org/10.1177/2158244020914554

Ryu, S., \& Sandoval, W. A. (2012). Improvements to elementary children's epistemic understanding from sustained argumentation. Science Education, 96(3), 488-526. https://doi.org/10.1002/sce.21006

Sandoval, W. A. (2005). Understanding students' practical epistemologies and their influence on learning through inquiry. Science Education, 89, 634-656. https://doi.org/10.1002/sce.20065

Simon, S., Erduran, S., \& Osborne, J. (2006). Learning to teach Argumentation: Research and development in the science classroom. International Journal of Science Education, 28, 2-3, 235-260. https://doi.org/10.1080/09500690500336957

Tao, Y., Oliver, M., \& Venville, G. (2013). A comparison of approaches to the teaching and learning of science in Chinese and Australian elementary classrooms: Cultural and socioeconomic complexities. Journal of Research in Science Teaching, 50(1), 33-61. doi.org/10.1002/tea.21064

Toulmin, S. (1958). The uses of argument. Cambridge, UK: Cambridge University Press.

Van den Akker, J. J. H. (2003). Curriculum perspectives: An introduction. In J. J. H. Van den Akker, W. Kuiper, \& U. Hameyer (Eds.), Curriculum landscape and trends (pp. 1-10). Dordrecht, Netherlands: Kluwer Academic Publishers. https://doi.org/10.1007/978-94-017-1205-7_1

Westbroek, H. B., Klaassen, K., Bulte, A., \& Pilot, A. (2010). Providing students with a sense of purpose by adapting a professional practice. International Journal of Science Education, 32, 603-627. https://doi.org/10.1080/09500690902721699

\section{Copyrights}

Copyright for this article is retained by the author(s), with first publication rights granted to the journal.

This is an open-access article distributed under the terms and conditions of the Creative Commons Attribution license (http://creativecommons.org/licenses/by/4.0/). 